This item was submitted to Loughborough's Research Repository by the author.

Items in Figshare are protected by copyright, with all rights reserved, unless otherwise indicated.

\title{
A persona-based approach to domestic energy retrofit
}

PLEASE CITE THE PUBLISHED VERSION

http://dx.doi.org/10.1080/09613218.2014.893161

\section{PUBLISHER}

Taylor and Francis / @ The Authors

VERSION

VoR (Version of Record)

\section{PUBLISHER STATEMENT}

This work is made available according to the conditions of the Creative Commons Attribution 3.0 Unported (CC BY 3.0) licence. Full details of this licence are available at: http://creativecommons.org/licenses/by/3.0/

\section{LICENCE}

CC BY 3.0

\section{REPOSITORY RECORD}

Haines, Victoria, and Val Mitchell. 2014. "A Persona-based Approach to Domestic Energy Retrofit". Loughborough University. https://hdl.handle.net/2134/14583. 


\section{A persona-based approach to domestic energy retrofit}

\section{Victoria Haines \& Val Mitchell}

To cite this article: Victoria Haines \& Val Mitchell (2014) A persona-based approach to domestic energy retrofit, Building Research \& Information, 42:4, 462-476, DOI: 10.1080/09613218.2014.893161

To link to this article: https://doi.org/10.1080/09613218.2014.893161

$$
\begin{aligned}
& \text { (c) } 2014 \text { The Author(s). Published by Taylor \& } \\
& \text { Francis. }
\end{aligned}
$$

\footnotetext{
曲 Published online: 08 Apr 2014.
}

Submit your article to this journal

LII Article views: 3508

Q View related articles $₫$

View Crossmark data $\nearrow$

Citing articles: 45 View citing articles 


\title{
A persona-based approach to domestic energy retrofit
}

\author{
Victoria Haines and Val Mitchell \\ Loughborough Design School, Loughborough University, Loughborough LE11 3TU, UK \\ E-mails: V.J.Haines@|lboro.ac.uk and V.A.Mitchell@|boro.ac.uk
}

\begin{abstract}
In order to improve the efficiency of the housing stock successfully, the offered technical solutions also need to meet occupants' needs and match their aspirations. Owner-occupiers present particular challenges: conflicting demands on their use of time and financial resources and their role as decision-makers for their own domestic renovation. A persona-driven study (based on user-centred design) was undertaken to explore the varying behaviours, attitudes and motivations towards home improvement for owner-occupiers who live in 'hard to treat' solid-walled dwellings. Five evidence-based personas are constructed that reflect archetypes, based on the outcomes of a qualitative study involving 33 owner-occupier householders in the East Midlands region of the UK. The adoption of a persona-based approach in response to the socio-technical challenges of energy renovation is important for understanding the specific drivers and appropriate range of policy responses for each persona. The persona development process is described and the success of the approach is evaluated in relation to the needs of policy developers, energy providers and product developers. Tailoring strategies to suit different personas will considerably enhance the diffusion of policy goals for low-energy retrofit and also allow business and technology developers to target an appropriate user.
\end{abstract}

Keywords: energy, homeowners, low carbon, motivation, personas, renovation, retrofit, user-centred design

\section{Introduction}

With $28 \%$ of the UK's energy used by the domestic sector (DECC, 2012) and at least $75 \%$ of the UK dwellings that will exist in 2050 already built (Wright, 2008) and a housing stock turnover of only about $1 \%$ per annum, there is a clear need for energy efficiency measures to focus on renovation of the existing stock. Whilst there are technical solutions that will minimize energy losses and reduce demand, these also need to meet people's needs and match their aspirations to be fully effective.

Owner-occupiers, who represent $65 \%$ of the UK housing stock (DECC, 2013), present particular challenges to policy-makers, designers and suppliers. As the decision-maker in the process, owner-occupiers face often conflicting demands upon their use of time and financial resources. In order to persuade this group to prioritize investment in energy renovation and domestic energy products and services, it is necessary to understand further their relationships to their homes and their attitudes towards making improvements to their homes. Hewitt (2012, p. 1) identifies that any technological intervention in addition to being cost-effective 'must be acceptable to the use, in terms of minimal disruption during installation, ease of use and alignment with lifestyle expectation'.

This paper reports the findings from a study of home improvement amongst a group of owner-occupiers in solid-wall dwellings (i.e. those built from brick or stone but with no air cavity between the layers of the external wall and so particularly hard to treat) and draws on tools from User Experience (UX) Design to help understand how these past home improvement projects can be used to describe different types of owner-occupiers in this context. As many home improvements include some aspect of energy efficiency (e.g. installing a new boiler and radiators, fitting draughtproofing or insulation), consideration of past home improvement activities provides a good proxy for prediction of future behaviour in terms of applying energy efficiency measures to the home. The aim was met though completion of the following objectives:

- a series of participative, semi-structured interviews were conducted with 33 owner-occupier 
householders who resided within 20 hard-to-treat solid-walled properties within the UK East Midlands region

- a structured but creative data analysis process was used to construct a set of five personas that communicate archetypal behaviours, attitudes and motivations towards home improvement for the sample population

- the potential usefulness of this persona set as a decision support tool was evaluated in relation to the needs of policy developers, energy providers and product developers

Personas are archetypal users who embody the goals and aspirations of real users in an easy-to-assimilate and personable form. Personas were first developed as a tool to support the development of software (Cooper, 1999). Cooper (1999) recognized that software developers often had a poor understanding of the intended users for their products and would make design decisions based on unfounded assumptions about people's preferences and skills or would revert to making decisions based on people like themselves. $\mathrm{He}$ proposed the use of persona characters to improve team communications and to provide a consistent reference point for design activities. Personas are now used widely within many sectors of the design industry, particularly in relation to the design of user experiences for digital products and services (e.g. McKay, 2013; Mulder \& Yaar, 2006). Personas can be assumption-based and such 'ad hoc' personas can be effective early in a project to articulate what is already known or being inferred about users (Adlin \& Pruitt, 2010). However personas are generally accepted to be only as good as the data on which they are built and should therefore be based wherever possible on robust qualitative research (Cooper, 1999). The study presented in this paper attempts to provide this robust underpinning to the resulting personas in the context of domestic renovation.

Like Munro \& Leather (2000), little distinction is made in this research between repair, maintenance and improvement, likewise the terms 'renovation' and 'refurbishment' are used interchangeably in this paper. Munro and Leather highlight the similarity between a repair project (e.g. where home owners replaced ill-fitting and draughty windows) and an improvement project (where replacement doubleglazing had resulted in redecoration) indicating how these activities are inextricably linked. Retrofit refers more specifically to the installation of an energysaving technology, retrofitted into an existing home (rather than being incorporated at the time of the build).

\section{Home improvement}

The literature reports that there are 15.5 million dwellings in England that are owner-occupied and 29\% of these (4.5 million) have solid walls (DEFRA, 2008a). Solid-walled dwellings are located throughout the UK with $75 \%$ of the total solid-wall housing stock located in urban centres (not city centres) and suburban residential regions (Vadodaria, Loveday, Haines, Mitchell, \& Bayer, 2010). While $30 \%$ of the stock is in London and less than 3\% is in the North East, the rest is located evenly in other regions of the UK. A total of $70 \%$ of the total solid-wall housing stock consists of end of terrace, mid-terrace, semi-detached and detached property types. Of particular relevance to this paper, $80 \%$ of the total solid-wall housing stock is owner-occupied and privately rented-occupied. Solidwall dwellings have an even mix of household composition, which includes couples less than 60 years of age with and without dependent children, couples above the age of 60 years with no dependent children, multi-person household and lone parents, and as a whole have a mean $\mathrm{SAP}^{1}$ rating of 49.8 (Vadodaria et al., 2010). As the least efficient sector of the housing stock, these hard-to-treat homes must be renovated to become more energy efficient. Whereas improvements to social housing can be undertaken at scale by a council or housing association, owner-occupiers have more freedom in renovating their homes (Baum \& Hassan, 1999) and so improvements to the owner-occupied stock relies on individuals being motivated to initiate or complete the work. Earl \& Peng (2011) identify motivations for undertaking home improvement activities to serve a particular purpose:

- to enhance the market value of the property or its potential rental yield

- to increase the properties' marketability

- to enable the home owner to meet new or existing lifestyle aspirations more cheaply than by selling up and buying an alternative property

- to enable the homeowner to enjoy enhanced social standing

- to meet psychological goals via the process of achieving the improvement

Given recent increases in fuel prices and incentives from government to reduce carbon emissions, an additional motivation might also be to reduce energy consumption. Gram-Hanssen (2014) reports other drivers for renovating dwellings, beyond cost and energy saving, including improving comfort, increasing indoor temperatures, maintaining against wear and tear, wanting a room or dwelling that is new and 
more fashionable, and even making a closer connection with the home, demonstrating the complexity of the topic. Gram-Hanssen categorizes reasons for renovation relating to the result (product) of the renovation, lifestyle and project factors. Peng (2012) classifies reasons as functional needs (similar to Gram-Hanssen's product), lifestyle pursuits (combining lifestyle and project) also mentioning investment as a factor.

Baum \& Hassan (1999) use contextual factors to identify what affects people's motivation to renovate. They found that those households with higher incomes renovate more often and that larger households undertake more renovations than smaller ones. Phipps (1983) asserts that a lack of finances is interpreted to be the major underlying constraint facing households, but income was not found to be a significant variable for some of Baum and Hassan's participants. They did find that renovation tends to occur more often in older dwellings and that housing preferences and needs change throughout a household's life cycle.

Munro \& Leather (2000) talk of 'consumption'-motivated expenditure ('nest building') on the home being prioritized over 'investment'-motivated work, which results in considerable disrepair within the owneroccupier stock. Although it might be expected that preservation of the heritage features of older homes would be a motivating factor for owner-occupiers (Earl \& Peng, 2011), Hills \& Worthing (2006) found that owners of character buildings invested in maintaining them only to avoid discomfort and costs of further deterioration and to get the satisfaction that went with keeping them in 'good order', rather than for cultural reasons. Munro \& Leather (2000) identify five household lifecycle stages as being relevant to domestic repairs (young household; household with children; empty nester pre-retirement; older household; and household dissolution/death). They note that expenditure on the house often competed with other spending priorities, even in those households that were less cash-constrained. Williams (2008) reports that more affluent households are both more likely to outsource routine or mundane home improvement tasks and undertake a much larger number of tasks themselves, showing a complex link between income and home improvement activity. The decision to outsource renovation work is influenced by trust in contractors. Mallaband, Haines, \& Mitchell (2013a, 2013b) report householders commissioning contractors who are not necessarily the most appropriate for a particular job, but are trusted, perhaps as a result of past experience or referral. Peng (2012) identifies a link between people lacking the desire to renovate their home and negative psychological attitudes towards renovation, which can include low trust in contractors. Peng (2013) also identifies DIY-renovators as having lower trust in contractors when compared with those who commission a professional to undertake domestic renovation work.

Despite the diversity of the population and variety of motivations and barriers to home improvement (Energy Saving Trust, 2011; Mallaband, Haines, \& Mitchell, 2012), there has been little categorization of types of home improvers. Baum \& Hassan (1999) identify two groups of renovators from research in Adelaide, South Australia: Non-mover Renovators and Mover Renovators. Whilst not relating directly to energy improvements, this categorizes people as those who are likely to stay in their homes and make improvements to them, and those who renovate with the primary motivation of selling their property and moving on. Munro \& Leather (2000) refer to this group as Potential Movers who undertake works to improve the saleability of the property. With the economic downturn in recent years and the consequent stagnation in house prices, Non-mover Renovators may be becoming the dominant group with homeowners more likely to stay in their home and make improvements than move on to make a profit (Halifax, 2010).

Watson \& Shove (2009) refer to a set of consumers outlined by one of their interview respondents, a design director of a major power tool manufacturer, which provides a limited typology of the do-it-yourself (DIY) market:

- 'Confident Enthusiasts' having DIY experience and continued enthusiasm for DIY jobs at home

- 'Pragmatists' with experience and enthusiasm but finding little reward in doing DIY jobs at present

- 'Newbies' or 'Assurance Seekers' who lack experience and confidence but want to achieve a desired effect

- 'Hobbyists' or 'Careful Perfectionists' who do not necessarily have experience but are driven by the pursuit of craft ideals and are concerned as much by the process as the final result

This typology, albeit offered by one individual, focuses on the attributes of DIY experience, their confidence to carry out DIY and satisfaction gained from the process. Earl \& Peng (2011) also mention 'self-confidence' as a prerequisite for embarking on home improvements, reflecting the need for suitable capacity in a householder's life to take on a renovation project. This was also found by Mallaband et al. (2012), where householders need sufficient personal capacity before they can embark on a project. For some people, the idea of home improvement activities is challenging and a source of excitement, for others it causes anxiety (Earl \& Peng, 2011). Earl and Peng also mention 
that householders procrastinate, rather than addressing repairs continuously, such that required repairs build up over time. They refer to a 'threshold of tolerance' that has to be reached before a householder will undertake some work on their property. This results in the piecemeal approach to renovation described by Fawcett (2013) and Fawcett \& Mayne (2012) rather than a planned, whole-house approach that may be more cost and energy effective.

Williams (2008) identifies two kinds of consumers engaging in DIY: those who embrace it willingly and those who do so only reluctantly. These are further subdivided into those who are willing DIYers who want to improve the value of their home, who undertake DIY for pleasure and those who seek self-identity from the end product. Those who are reluctant can felt forced into DIY for economic reasons or have problems finding and using appropriate tradespeople.

Whilst these papers provide some categorization of home improvement types within the population, past attempts to categorize the population within the energy demand reduction context have been limited. Archetypes are already commonly used in energy modelling to simplify the complexity of the housing stock, by adopting a number of dwelling archetypes which together represent the whole stock (Firth, Lomas, \& Wright, 2010), but these relate only to the buildings and not the households who live within. DEFRA (2008b) classifies seven population segments based on people's willingness and ability to act pro-environmentally: Positive Greens; Waste Watchers; Concerned Consumers; Sideline Supporters; Cautious Participants; Stalled Starters; and Honestly Disengaged. Zhang, Siebers, \& Aickelin (2012) highlight the limitations that this approach takes, as the effects of physical attributes of the home are ignored; the approach is also not at a household level. Zhang et al. (2012) propose eight archetypes of UK residential energy consumers based on three dimensions: energy efficiency level of the property, 'greenness' of the household's behaviour; and length of daytime occupancy period: Pioneer Greens; Follower Greens; Concerned Greens, Home-stayers; Unconsciously Wasters; Regular Wasters; Daytime Wasters; and Disengaged Wasters. Whilst these relate to the household, they are not focused on home improvement activities and the potential for energy saving renovation.

In a report for the Joseph Rowntree Foundation into the market potential for smart homes (Pragnell, Spence, \& Moore, 2000), three broad segments are identified: The Interested, The Ambivalent and The Uninterested. Whilst these are likely to cover the whole population, the lack of detail or focus provides little assistance to the designer or developer. More recently, market segments have been used by utility companies to target service or product propositions, but these remain commercially confidential and so do not aid the wider community.

The authors conclude from the literature that there is a lack of clear and targeted information that describe the range of existing householders within the context of domestic renovation, particularly owner-occupiers, to help guide designers and developers towards solutions that meet individual needs. Whilst it is impractical to provide bespoke solutions for the whole population, identification of needs for groups of similar individuals does provide a valuable approach and this paper offers a possible way forward through the use of personas.

\section{A user-centred design approach to energy demand reduction}

Policy measures are attempting to encourage and support individuals towards reducing their domestic energy demand, e.g. through the Green Deal in the UK; and scientific advances are progressing the technical measures available through, e.g. solid-wall insulation or improved heat pump design. However, the issues involved in reducing energy demand are complex and interrelated and so require a holistic or systems perspective in order to ensure they are successful. Rittel \& Webber (1973) described these types of societal problems as 'wicked' problems; they are illdefined, they have no clear 'stopping point', they may only achieve a 'good enough' endpoint, they are without a time span, and the solutions are intertwined with the problem. As domestic energy demand reduction is a wicked problem with complex sociotechnical components, user-centred design (UCD) lends itself well to offering a systemic approach, or suite of approaches. By focusing on the needs of the user and considering the range of activities undertaken in the context of the wider domestic environment, it is possible to consider the issue from a broader perspective.

UCD offers a process by which the user is considered central to the system and any design solutions (which could be products, services or systems); it provides a means to ensure the context of use and user needs are included within the design process, by considering physical, cognitive, social and cultural factors (Gould \& Lewis, 1985). To achieve most success, users should be considered from the outset of a design process, as well as throughout, including continued consultation even after a product, service or system is in use. However, it can be difficult for designers and technology developers to identify users and research their needs, particularly when the market is diverse or ill-defined (Kujala \& Kauppinen, 2004).

Within UCD, personas have emerged as a popular method to manage representation of users within the 
design process (Marshall et al., 2013). Personas should not be confused with market segments. Market segmentation is used primarily to identify groups of consumers who will be receptive to a similar product, service or marketing campaign. Segments are usually defined by socio-demographic variables such as age, gender, income and location, although more sophisticated tools including psychographics (Wells, 1975) may also utilize analysis of psychological and behavioural variables such lifestyles, values and decisionmaking patterns. Typical psychographic variables include activities, needs, values and personality. Whereas market research techniques using these psychographic variables seek to provide a quantitative breakdown of the likely market, based on large representative sample sizes, personas encompass a similarly wide range of variables but utilize rich qualitative data from much smaller samples, with the primary purpose to aid design decision-making (Pruitt \& Adlin, 2006). Cooper \& Reimann (2003) acknowledge the pre-existence of psychographics, but market segmentation and personas should be viewed as complementary tools (Brechin, 2008).

Pruitt \& Adlin (2006) highlight three particular benefits related to using personas. Firstly, personas make any assumptions being held by the design team explicit and therefore help build a shared understanding of who is being designed for. Secondly, personas support decision-making by providing a small number of specific users to design for. Although focusing the design of a product or service to meet the needs of a narrow group of users can sound dangerously limiting, designing for a few well-defined personas provides meaningful constraints and boundaries to the problem space and therefore is likely to improve the quality of design decisions (Dorst \& Cross, 2001). Finally, as personas contain personal and believable characteristics, they are more engaging than other representations of user data. A well-defined persona will therefore encourage empathy towards users and engage the interest of stakeholders.

However, not all are in favour of personas (Massanari, 2010). DeVoil (2010) questions the validity of using fictitious characters within design and advocates in line with Hackos \& Redish (1998), the use of 'user profiles' that describe real rather than archetypal people. Rather than speculating how an imagined persona may react or behave, he argues that it is better to maintain an on-going dialogue with a real person, who may provide messy or inconvenient answers. Whereas any user-centred practitioner will support this view, it is not always practical or cost-effective to continuously or repeatedly engage users in the design process. This view also ignores the need to provide an evidence based description of user needs for a diverse range of stakeholders rather than a single design team. Personas are only as valid as the data on which they are built and a common criticism of the technique is that too many personas are not based on empirical evidence but assumption-based (Saffer, 2007); however, this criticism can be negated when personas are grounded in user research.

The personas within this research were primarily created to describe the archetypal approaches to home improvement that emerged with a view to understanding the barriers and opportunities to future ecorenovation. The developed set of home improvement personas represent the diversity of owner-occupiers with regards to the attitudes and motivations illustrated by the study population.

\section{Methods \\ Data collection}

Rich qualitative data were collected from a group of owner-occupiers who live in solid-walled dwellings. A study, which formed part of a larger research project on retrofit energy saving technologies for owner-occupiers (CALEBRE), was conducted with 20 households from the East Midlands area of the UK, with 33 participants contributing to the study, just exceeding the sample size of 30 suggested by Robson (2011) for single-group observations. The four-year CALEBRE research project aimed to establish a validated, comprehensive mechanism for reducing UK domestic carbon emissions within solid-walled housing that is acceptable and appealing to users. Although this project had a strong focus on energy, this study focused on the broader aspect of home improvement. Although the researchers were interested to see how home improvements might be linked to energy saving, this was not a key feature of the data collection, as its aim was to determine what other barriers and motivations existed.

The participants were selected to represent a wide range of dwelling and household types, representing a range of family structures, incomes and social statuses to provide a spread of participants. As it was never intended to be a statistically representative sample, this allowed for a snapshot of different domestic situations to be explored in detail and care was taken in the sample selection to ensure a broad spread of participants. Household characteristics considered included number of permanent occupants (mean $=3.3$ people, range $=1-7$ people $)$, household income band (mean $=£ 40000-50000$, range $=$ less than $£ 10000$ to more than $£ 80000$ ), number of permanent adult occupants (mean $=2.1$ people, range $=1-5$ people) and their ages (mean $=48.2$ years, range $=18-80$ years), number of children (mean $=$ 1.1 children, range $=0-4$ children) and their ages (mean $=6.9$ years, range $=$ less than 1 to 17 years), year of dwelling construction (mean $=1900$, range 
$=$ 1840-1930), location (city centre-rural), type of building (terrace-detached) and length of ownership (mean $=16.6$ years, range $=3-35$ years $)$. Further details of the sample and its comparison with the UK stock are presented in Vadodaria, Loveday, \& Haines (2014).

Interviews were conducted with all adult members of the household wherever possible using a semi-structured set of questions and a novel timeline tool, developed for the study (Haines, Mitchell, \& Mallaband, 2012; Mallaband et al., 2013a). Participants were encouraged to use participative storytelling methods to capture, in rich detail, their past home improvement experiences, co-creating the timeline to develop a shared representation of the home improvements undertaken. From the interviews it was clear that renovation was not only an activity undertaken by the householders to improve their home, but also was a memorable emotive user experience, whereby satisfaction may be gained from learning new skills, completing a task or gaining a better home, replicating the complex accounts of home improvement activities reported to Munro \& Leather (2000). It was apparent that members of a single household had different perspectives on, and attitudes towards, their home and renovation. These distinctions were captured within the conversations so they could be reflected in the resulting personas.

\section{Development of the personas}

Data collected in these interviews were used to create personas, developed using a process adopted from User Experience Design (Goodwin, 2010). Whereas personas are ideally developed to support the development of a particular product or service, the goal of this research was much broader. The home improvement personas were intended to support the needs of a wide range of policy and technology developers. The resulting personas were therefore designed to represent archetypal attitudes and motivations for making home improvements rather than to just support the design of particular product or policy. Data from the interviews were transcribed in full and then the following steps were followed to create the personas:

- Behavioural and demographic variables were identified that were salient to understanding home improvement and also the energy demand reduction context. These variables emerged from a thematic analysis of the transcribed data, identifying a total of 26 variables that could be described in objective terms. These were expressed on a continuum, from low to high or as mutually exclusive variables. Variables included: Having a high or low motivation for DIY; Being a 'modernizer' or a 'restorer'; Having a high or low sensitivity to price; Having a high or low concern about climate change; Liking a challenge or not liking a challenge; Having a high or low expectation of thermal comfort in the home.

- Interviewees were mapped to the variables along each of these spectrums and in relation to each other, as shown in Figure 1. Based on their responses in the interviews, a tag representing each person was placed on each of the various scales by the researchers. Where there was uncertainty, evidence from the transcripts was identified to ensure appropriate placement.

- The next stage was to identify and explain potential patterns in reference to the primary research. For example, two or more people who occur together on at least a third of the variables might be said to represent a pattern, but a meaningful reason for creating this pattern had to be apparent from the interview data. Transparent overlays were used to visually highlight groups of individuals where they sat together on a number of scales. Outliers were also of interest as they may be indicative of a separate persona.

- Patterns were then clustered into skeleton personas, identifying particular common attributes of

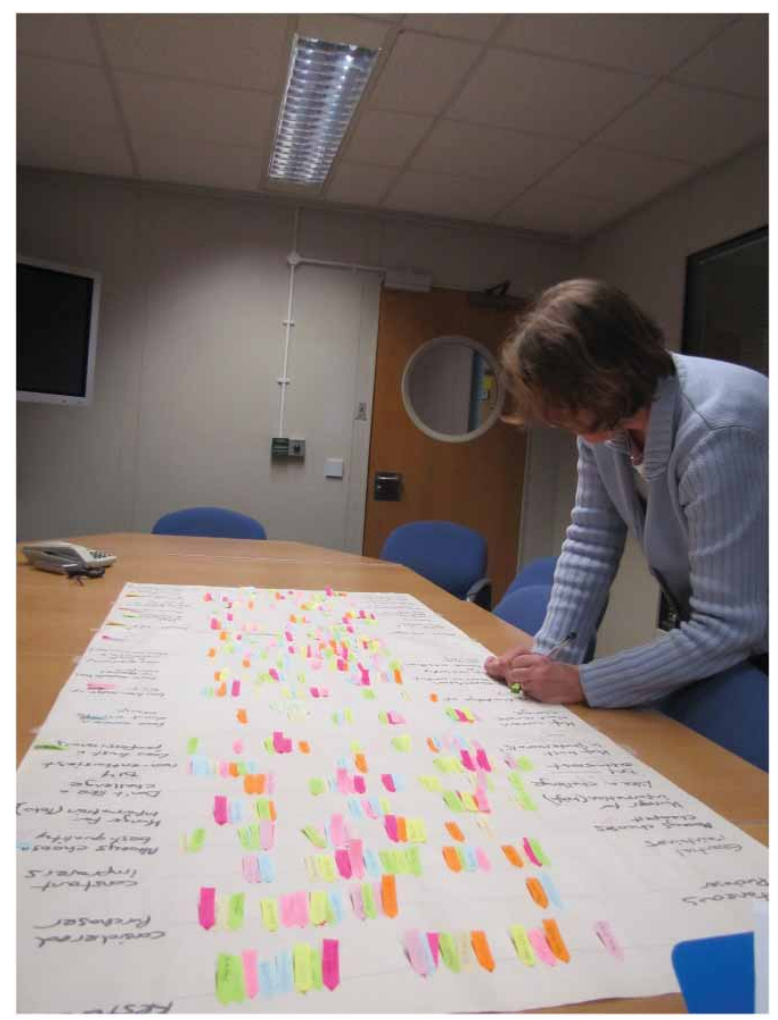

Figure 1 Mapping participants onto the variables 
certain groups of people, again with frequent reference to the interview transcripts.

- The next stage was to clarify distinctions and add detail to the skeleton persona characters by assigning characteristics from the data, such as demographic data, behaviours, frustrations, skills and attitudes. Some criteria which were important, but not critical, to defining the patterns were identified, e.g. gender, experience with technology. Goodwin (2010) recognizes that these characteristics should be included within the persona set and so they were assigned in a way that enhanced the believability of each persona.

- The final stage was to develop a narrative for each persona and to select realistic photos and quotes from the primary data in order to make the personas into believable characters.

Goodwin (2010) recommends that the number of final personas should be limited to between three and seven. From this research five evidence based personas emerged, two of which had subtypes, making seven in total.

\section{The developed personas}

An example persona developed from the data set presented in Figure 2 and Table 1 shows the full set without the graphical layout. This set represents archetypal owner-occupier families that live in solid-wall (hard to treat) UK homes. The primary purpose of the persona set is to inform the design of retrofit energy saving measures by providing insight into the everyday domestic contexts within which these measures will need to fit. In particular the personas represent:

- the attitudes and motivations of homeowners related to making improvements to their homes

- the difficulties relating to making home improvements

- how homeowners go about making these improvements

- how these attitudes, motivations and behaviours result in opportunities and barriers to retrofit

To aid quick visual comparison between the personas, some of the variables were summarized as a set scales on the persona sheet and the personas were allocated a point on the scale that best represented their type (Figure 2). These were initially based on the patterns that had emerged from the research data. However these points on the scales were validated by the researchers independently assigning points on the scales. In most cases the researchers showed good agreement and the scale marker was fixed, however in one particular case there was less consistency. For 'Interest in energy saving' there was less agreement, as this was something that had not been explored directly in the home improvement orientated interviews. Householders had been asked about any problems that existed in their homes that related to being too hot or cold, damp and condensation, draughts or stuffiness, but not within the direct context of energy saving. For this scale, a decision was made based on the overall characteristics of the persona. For example, the Idealist Restorer (Figure 2) has a strong interest in energy saving as a construct of quality, reflecting an interest in clever technology, but only when this does not contradict with their primary goal of restoring the character of their property. As such, the Idealist Restorer has a relatively high interest in energy saving.

\section{Evaluation of the personas}

To evaluate the personas further, the set was sent to a small number of key people to review and comment. These people included a research manager in the energy field, a customer insights expert working for a major utility company, an energy policy expert, an energy consultant and members of the academic project research team in which the study was conducted. All said that the personas described the range of owner-occupies well, in terms of their attitudes towards making home improvements. The feedback on the personas was generally consistent across all respondents, with positive comments from all. The personas were felt to 'bring the customer to life', allowing the user to see the person behind the data by providing value and richness to the core groups and making them relevant. All mentioned that income and the ability of the householder to pay could also have been included as a key variable. This could include an individual's access to finance, perhaps to indicate the kinds of measures that each persona could afford; however this aspect was outside the original study aims and so the data were not available when building the personas. Again, this is an area where further work could contribute. The respondents were also asked if they felt any key personas were absent. The most prominent omission was a persona relating to the social housing sector, and some respondents mentioned the private rented sector, particularly living in apartments. However, both these fell outside the scope of the original research which was focused on owner-occupiers. One respondent did suggest an 'Eco-Idealist' persona to parallel the Idealist Restorer. This persona was also identified by the researchers as missing from the set, as the small sample that provided the original 


\section{The Idealist Restorer - the property is a project}

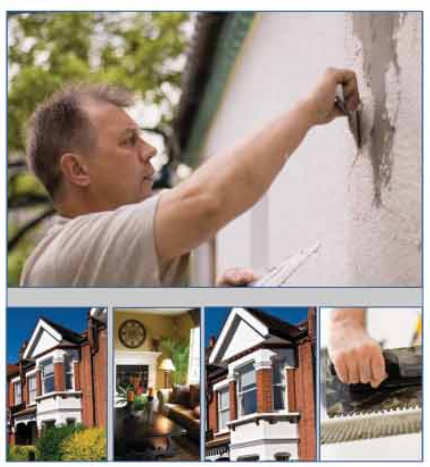

"If you're going to do a job, you might as well do it well"

John \& Shena brought their house in a run down condition 5 years ago. They are seeking to achieve an aesthetic, tasteful home of character that exudes both individuality \& quality. John likes to carry out work himself as he enjoys mastering practical skills but also wants to ensure a quality job. He is the dominant decision maker regarding home improvement \& has a grand plan for the property. He likes to ensure that underlying structural issues are sorted before more cosmetic improvements are made.

\section{John Silverstone age 43}

Lives with his wife Shena $\& 2$ children in a terraced 4 bed Victorian villa in a North London suburb. He is an IT manager for a large firm of accountants.

\section{Attitudes \& Motivations}

- Motivated to live in an older property because of the character \& the opportunity it provides for restoration \& improvement. Values the aesthetic period features \& space afforded by older homes

- John wants to restore as many original features within the home as possible but not at the expense of aesthetics, comfort \& convenience. Although he wishes to keep the sash windows, he has replaced the quarry tile floor in the hallway with laminate flooring

- Motivated to learn new DIY skills \& wants to do things thoroughly

- Energy efficiency is perceived as a construct of quality but aesthetics \& comfort are valued more highly

Pain Points

- Shoddy workmanship

- Lack of professionals with specialist knowledge of older properties

- Poor quality products or materials

- His own lack of time
Opportunities for Retrofit

- Very open to retrofitting energy efficiency measures \& in an optimal order if the aesthetics of the home are respected

- Interested in 'clever' energy saving technologies but only if the character of the home can be maintained

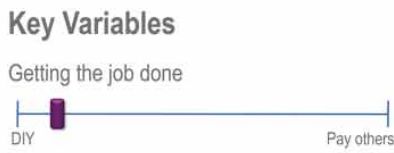

Trust in professionals

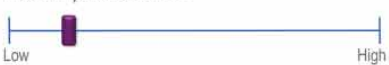

Tolerance of disruption

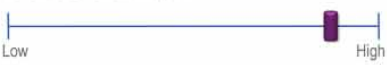

Hunger for information

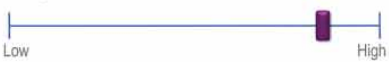

Interest in energy saving

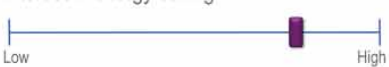

Figure 2 Example persona - the Idealist Restorer

data did not include anyone who had this characteristic, but anecdotally it was recognized as an archetype, which could present an example of an early adopter of new technology. Whilst this persona could represent an important stimulus to the market, as the personas were data driven, the Eco Restorer was not included to the original set, but further data collection could focus on this particular subtype to extend the set.

\section{Discussion}

The literature showed few categorizations of people in relation to home renovation to aid those developing energy efficiency interventions. However, the need to understand people's motivations and preferences is paramount if we are to encourage owner-occupiers to refurbish their homes with energy efficient technologies, given the requirement for this group of householders to be proactive.

The developed set of personas presented here demonstrates that householders, even within the confines of owner-occupiers in solid-wall dwellings, are diverse and their goals and motivations need to be considered as subsets of the whole population. In some cases, the personas resonate with the limited findings from the literature. The Property Ladder Climber persona aligns with the 'mover renovators' identified by Baum \& Hassan (1999) and the 'potential movers' (Munro \& Leather, 2000); all have similar aspirations to renovate and move on. The desire to improve one's home, to increase its value or marketability (Earl \& Peng, 2011) provides an important opportunity for policymakers, as these people provide a stimulus to the market. Provision of finance through schemes such as the Green Deal should offer opportunity for the Property Ladder Climbers to undertake energy efficient renovations as part of their home improvements, as they are motivated to withstand the disruption and effort that may be involved.

The Affluent Service Seeker persona also wants to increase their property value, but in the longer term. They see their home as an investment for which they have worked long and hard and so its renovation is, as Munro and Leather concur, as much 'investment' as 'consumption' motivated. The inclusion of only two investment motivated personas in this set (Property Ladder Climbers and Affluent Service 
Table 1 Key information from the set of home improvement personas

\begin{tabular}{ll}
\hline $\begin{array}{l}\text { Persona (including } \\
\text { subtype) }\end{array}$ & Opportunities for retrofit \\
\hline
\end{tabular}

The Idealist Restorer: The property is a project

The Affluent Service Seeker: The property is a pleasure

The Property Ladder Climber: The property is a step up

The Pragmatist: Subtype - Functional The property is a place to live
Motivated to live in an older property because of the character and the opportunity it provides for restoration and improvement. Values the aesthetic period features and space afforded by older homes

Wants to restore as many original features within the home as possible but not at the expense of aesthetics, comfort and convenience. Although they wish to keep the sash windows, they have replaced the quarry tile floor in the hallway with laminate flooring

Motivated to learn new DIYskills and wants to do things thoroughly

Energy efficiency is perceived as a construct of quality but aesthetics and comfort are valued more highly

Motivated to live in an older property because of the character, idyllic rural location large garden and useful outbuildings. Accepts that older properties are expensive to maintain and views spending on the property as a way to preserve and add value to the investment in the property

Seeks luxury and quality but also value for money. Known to be financially savvy. Values comfort over financial saving

Carries out very little DIY through choice but likely to be less physically able than when they were younger

Energy efficiency is perceived as difficult to achieve in a large old property but this persona is keen to take advantage of any grants or incentive schemes available

Motivated to live in an older property by the potential it offers to add value to its resale value through renovation

Happy to borrow money in the short-term to finance home improvements, paying these back when the property is sold

Enjoys developing their DIY skills as the projects get bigger with each property they buy

Open to consequential improvements as they are thinking at a whole-house level but these improvements must lead to financial gain at the point of resale

Energy saving beyond current building regulations is not a priority

Motivated to live in an older property because of the layout and room size that accommodates a full and active family life

Home improvements are seen as a hassle rather than a hobby; they take time away from more important things - hobbies and family time

Not particularly interested in keeping older features of the property, but places greater value on convenience

Concerned about the environment and climate change, When finance becomes available.
Very open to retrofitting energy efficiency measures and in an optimal order if the aesthetics of the home are respected

Interested in 'clever' energy saving technologies but only if the character of the home can be maintained

Open to incentive schemes and polices that generate income for the homeowner or add value to the property

Will choose to use specialist professionals to ensure a quality job

Open to the use of finance schemes if these are cost-effective within the context of 'improving to sell'

Unlikely to consider technologies with long payback times unless the cost of installation is passed on

When things wear out or go wrong

At the time of purchasing the property

When re-purposing a space or extending the home as a result of their family values. 


\begin{tabular}{|c|c|c|}
\hline $\begin{array}{l}\text { Persona (including } \\
\text { subtype) }\end{array}$ & Key features & Opportunities for retrofit \\
\hline \multirow[t]{4}{*}{$\begin{array}{l}\text { The Pragmatist: } \\
\text { Subtype - Aesthetic } \\
\text { The property is a home }\end{array}$} & \multirow{2}{*}{$\begin{array}{l}\text { Motivated to live in an older property because of the } \\
\text { character and space it offers } \\
\text { Enjoy having a project on the go but improving or } \\
\text { updating the decor, furniture and appliances within } \\
\text { the home will be of higher priority than repurposing of } \\
\text { space or non-essential maintenance }\end{array}$} & $\begin{array}{l}\text { When they first purchase the property or within } \\
\text { the regular cycle of decorating and } \\
\text { refurbishment }\end{array}$ \\
\hline & & \multirow[t]{3}{*}{$\begin{array}{l}\text { The order of retrofit will be driven by aesthetic } \\
\text { priorities, e.g. the desire for new kitchen may } \\
\text { lead to a new boiler }\end{array}$} \\
\hline & $\begin{array}{l}\text { Likely to cover up some issues like damp through } \\
\text { frequent redecoration rather than fix the underlying } \\
\text { cause }\end{array}$ & \\
\hline & $\begin{array}{l}\text { Values 'off the shelf' solutions, preferring to finance } \\
\text { these from savings or windfalls rather than loans. } \\
\text { Want a neat and tidy job to be done, with a good- } \\
\text { quality finish }\end{array}$ & \\
\hline \multirow{4}{*}{$\begin{array}{l}\text { The Stalled: Subtype - } \\
\text { Lack of Finance } \\
\text { The property is a shelter }\end{array}$} & $\begin{array}{l}\text { Wants a warm, comfortable home, but is not extravagant } \\
\text { in their requirements }\end{array}$ & \multirow{4}{*}{$\begin{array}{l}\text { Limited to when grants are available } \\
\text { Will undertake consequential improvements if } \\
\text { dictated by grant scheme }\end{array}$} \\
\hline & $\begin{array}{l}\text { Wants to feel safe and secure in their home and be } \\
\text { assured that any work undertaken by tradespeople is } \\
\text { not exploiting them financially or putting them in } \\
\text { danger }\end{array}$ & \\
\hline & $\begin{array}{l}\text { Frugal and interested in saving energy primarily to save } \\
\text { money. They are positive towards opportunities to } \\
\text { improve the warmth and security of their home }\end{array}$ & \\
\hline & $\begin{array}{l}\text { Leaves parts of the property unheated through the } \\
\text { winter, but uses draughtproofing to increase comfort }\end{array}$ & \\
\hline \multirow{3}{*}{$\begin{array}{l}\text { The Stalled: Subtype - } \\
\text { Pressures of Life } \\
\text { The property is a } \\
\text { necessity }\end{array}$} & $\begin{array}{l}\text { Does not have the time, emotional energy or financial } \\
\text { resource to undertake home improvements at } \\
\text { present }\end{array}$ & \multirow[t]{3}{*}{ Almost none at present } \\
\hline & $\begin{array}{l}\text { Will use a trusted, known professional to help with any } \\
\text { essential jobs around the property but won't } \\
\text { undertake any major projects }\end{array}$ & \\
\hline & $\begin{array}{l}\text { May consider taking a loan to fund essential } \\
\text { maintenance but they prefer to wait and use savings } \\
\text { when they can afford }\end{array}$ & \\
\hline
\end{tabular}

Seekers) also reflects the prioritization of consumption motivated renovation. Based on this small sample, this suggests that developers of energy efficient interventions should recognize that some householders will want to undertake improvements that improve their quality of living, whether this is a warmer living environment, reduced bills, or improvement in the decor (perhaps through removal of mould or condensation), rather than increasing the value of their home.

This nest-building behaviour is evident in the Pragmatist personas, for both subtypes: Functional and Aesthetic. Priorities here are for a comfortable family home that meets the everyday requirements of the household. Homes were seen as central to the respondents' lives in Munro \& Leather's (2000) research, with work undertaken on the home often seen completely independent to the value that the improvement might add. Energy saving technologies are only likely to be taken up if they fit in with the household's lifestyle; householders will not be tolerant to significant disruption if it upsets everyday life, unless the gains from the improvement impact on the space or comfort of the home. For example, external wall insulation that does not reduce room sizes or cause significant disruption to daily life during installation may be more acceptable than internal insulation that will impact in the short and longer term, even if it is cheaper to install and more efficient. Gram-Hanssen (2014) also identifies the prioritization of indoor aesthetics and functions over energy saving renovations from her sample. Additionally, returning the home to its former (or improved) state of decoration as part of the job will be important to these personas. It would unacceptable to leave rooms needing finishing or redecoration after the installation of an energy efficiency measure. This would need to be provided as part 
of the job in order to fully meet the Pragmatist personas' needs.

In line with the findings of Williams (2008), the set of personas includes two subtypes that are Stalled - by Pressures of Life, such as illness, job or family changes; and by Lack of Finance. Whilst these two personas are unlikely to take on major renovation projects, they do provide future potential if their circumstances change. For some stalled households, the finance or capacity may return, once the temporary hurdle is overcome, or external finances can be provided, e.g. through the Green Deal. But for some, in particular older householders, this stalled position may be permanent. Munro \& Leather (2000) also identify older householders with limited funds and lack of willing to face disruption, which could suggest a third 'stalled' persona who just do not want to renovate. This could be as a result of an inability to make a decision or simply lack of interest. Earl \& Peng (2011) refer to people discounting the future 'hyperbolically, rather than exponentially', thereby giving undue weight to the immediate costs of home improvement. As a result, there is a cycle of continuous procrastination. For these owneroccupiers, policy offerings such as grant schemes may have no effect, regardless of their value.

It was evident from some of the interviews that some householders enjoyed the challenge of learning a new skill through DIY, or took pleasure from the completion of the renovation task. The Idealist Restorers persona demonstrates this most strongly, reflecting that the home improvement is an experience as well as a task, placing a high priority on quality. Watson \& Shove (2009) talk of the value in developing a competence or skill and Gram-Hanssen (2014) identifies that renovation can be a creative task which some people relish; these are key features of the Idealist Restorer persona. These people are unlikely to allow a tradesperson to undertake significant work on their home without close consultation and supervision. Tradespeople making energy efficient renovations will need to ensure they are expertly skilled and prepared to work closely with this type of person in order to complete a satisfactory job. The Affluent Service Seeker is less likely to undertake work themselves and requires the tradesperson to be reliable, trustworthy and produce work of a high quality; in return this persona will pay for the service. Munro \& Leather (2000) report serious problems in finding a competent and trustworthy builder, which is a key requirement for these two personas.

To develop the understanding and application of the personas further, each has been considered in relation to a particular intervention - the installation of external wall insulation, a particularly relevant measure to the solid-wall properties owned by the participants in this study. Consideration of this measure for each persona and the design and policy implications, developed from the authors' immersion in the data and understanding of the measure in practice, are set out in Table 2.

A number of the developed personas have little interest in energy saving, and none see this as the primary motivator for renovation. This has obvious implications for policy and design measures that are aiming to reduce carbon emissions and presents a significant challenge. The personas provide insights into other motivations for householders which can perhaps be used as opportunities to encourage engagement with energy saving retrofit as a by-product. However, there remain some owner-occupiers that will never engage in renovation, perhaps as their circumstances mean they remain stalled or because they see no short or long term reason. Those who are elderly may feel their life expectancy is too short to make a long-term measure worthwhile and so policy measures that provide short term payback (not necessarily financial) will be needed to encourage these people take the decision to renovate their properties. These measures might include cashback incentives or measures delivered as a package that promotes the provision of warmth and comfort rather than energy saving.

The persona set developed from this study has similarities to the some of the types of home improvers described in the literature, but have extended the detail for this particular context and brought together the rather disparate existing knowledge into one resource. Whilst elements of the Property Ladder Climbers and Stalled personas are more clearly identified in previous literature, the requirements of the Pragmatists, Affluent Service Seekers and Idealist Restorers are novel. Gram-Hanssen's (2014) survey of Danish householders identifies people renovating their property as a continuous activity, but recognizes that these people will have varying goals and motivations. The importance of understanding lifestyles, status and consumer choice as part of the renovation process is key. Gram-Hanssen notes, importantly that, in most cases, energy efficiency is not the main renovation rationale, which continues to present a challenge to the policy-makers and technology developers alike.

This persona set describes individuals, but it is likely that a household will comprise of more than one persona type within the decision-making team. It was evident from the interviewed sample that couples had different approaches to home improvement, representing different, sometimes conflicting, personas. This can create tensions where there is disagreement in priorities and can cause stagnation where two or more parties cannot reach agreement on how to proceed. In some cases, a shared decision can be made, but this could be a compromised decision, resulting in a less than ideal outcome. In other cases, there may be a dominant 
Table 2 Possible impact on each persona of external wall insulation (EWI) as a renovation measure

\begin{tabular}{|c|c|}
\hline $\begin{array}{l}\text { Persona (including } \\
\text { subtype) }\end{array}$ & Requirements of the persona from EWI \\
\hline $\begin{array}{l}\text { The Idealist } \\
\text { Restorer }\end{array}$ & $\begin{array}{l}\text { The Idealist Restorer will only be interested in EWI if it } \\
\text { will maintain the traditional appearance of the } \\
\text { property, including being sympathetic to any } \\
\text { architectural features. This may require use of } \\
\text { traditional materials as a veneer and specialist } \\
\text { detailing }\end{array}$ \\
\hline & $\begin{array}{l}\text { The Idealist Restorer will be positive about the benefits } \\
\text { from this new technology but will want to } \\
\text { understand the detail of the process and benefits in } \\
\text { advance }\end{array}$ \\
\hline
\end{tabular}

The Affluent Service Seeker

\section{The Property Ladder Climber}

The Pragmatist: Subtype Functional

Energy saving will not be the primary objective of the refurbishment

EWI must improve the indoor environment, in particular comfort levels

EWI must add financial value to the property in the medium to long term

As this persona has little tolerance to extended periods of unplanned disruption, projects must run to plan

The Property Ladder Climber's primary requirement is for enhancement of the property value, so EWI must add financial value to the property in the short term

Increased saleability of the property is also key and so the appearance of the property must be enhanced by EWI

The Functional Pragmatist is most likely to consider $\mathrm{EWI}$ as part of a wider renovation project, e.g. when adding an extension to the property
Implications for policy and technology design

The advantages and disadvantages of EWI must be made explicit in advance and in detail. This might require the provision of expert, independent, but bespoke, advice relating to the issues of older properties in particular

It must be possible for EWI to be fitted without losing architectural or aesthetic features of the property

EWI must be offered in a range of finishes, including the use of traditional materials. The use of traditional finishes must meet the approval of planning requirements

Policy measures must allow part-DIY installation so that the Idealist Restorer can be remain in control of the retrofit

This persona may take years to decide to install this measure and will only proceed when they feel they have adequate information and time available to dedicate themselves to the project

Accredited suppliers must be skilled to supply a range of services, or work under a project manager who can draw these together seamlessly, as a 'one-stop shop'

Financial penalties could be applied if EWI is not fitted to an agreed time plan, extending the accreditation requirements already in place

EWI must be available in a range of quality finishes to ensure the look of the property is not compromised

The Functional Pragmatist will enjoy the improved comfort of the home, without the loss of internal space, but the EWI must not compromise usable garden or passageway space outside as these outdoor spaces may be important to family living, e.g. patio use or for pushchair or bicycle access
Energy saving is likely to be a blind spot for this persona as comfort and property value are primary concerns

Interested in the Green Deal if it makes financial sense, elsewhere or personal savings

Finance schemes must offer short term benefits and must not put off future buyers through perceived long term burdens

Policy measures must allow part-DIY installation so that the Property Ladder Climber can minimize costs

Energy saving is of little importance to this persona, unless it relates to improved saleability of the property. Policy measures that relate to energy performance will need to be mandatory in order for this persona to respond

The Pragmatists will be cautious about taking on loans for large renovation projects and so financial packages must be competitive with other loans available and could reward part payment from savings. The Green Deal packages may not be competitive, given the likely potential for this type of persona to extend their mortgage at a more favourable interest rate

To appeal to this type of persona, EWI will need to be provided as a complete package, perhaps including redecoration to complete the job, under a project manager who guarantees the quality and time completion of the work but likely to have access to better loan rates 


\begin{tabular}{|c|c|c|}
\hline $\begin{array}{l}\text { Persona (including } \\
\text { subtype) }\end{array}$ & Requirements of the persona from EWI & Implications for policy and technology design \\
\hline $\begin{array}{l}\text { The Pragmatist: } \\
\text { Subtype - } \\
\text { Aesthetic }\end{array}$ & $\begin{array}{l}\text { The Aesthetic Pragmatist may also consider EWI as } \\
\text { part of a wider renovation project, but will have an } \\
\text { enhanced focus on the appearance of the property. } \\
\text { Although there will not be such a focus on traditional } \\
\text { features as the Idealist Restorer, it is important for } \\
\text { the renovated property to look neat and tidy, as well } \\
\text { as saving energy and improving comfort } \\
\text { As this persona has little tolerance to extended periods } \\
\text { of unplanned disruption, projects must run to plan }\end{array}$ & $\begin{array}{l}\text { The appearance of the EWI will be of less importance to } \\
\text { the Functional Pragmatist, but energy saving, cost } \\
\text { and expediency of the retrofit will be key } \\
\text { The Aesthetic Pragmatist will want EWI that looks smart } \\
\text { and performs well, but will focus more on value for } \\
\text { money than the traditional appearance of the finish }\end{array}$ \\
\hline $\begin{array}{l}\text { The Stalled: } \\
\text { Subtype - Lack of } \\
\text { Finance }\end{array}$ & $\begin{array}{l}\text { The persona Stalled by Lack of Finance will consider } \\
\text { EWI only if it is available by means of a grant } \\
\text { They will appreciate the long-term benefits of } \\
\text { improved comfort and, possibly reduced bills, } \\
\text { (depending on take-back), but will not be in a } \\
\text { position to renovate without external support }\end{array}$ & \multirow{2}{*}{$\begin{array}{l}\text { There are limited opportunities for these Stalled } \\
\text { personas, unless policy measures can provide } 100 \% \\
\text { finance and practical support through delivery of a } \\
\text { renovation service. This still may be too difficult for } \\
\text { some to take on, as other pressures mean that they } \\
\text { will not improve the energy efficiency of their } \\
\text { properties under any circumstances. The only options } \\
\text { for these people is to wait until they move out of this } \\
\text { persona type, or provide measures that will assist } \\
\text { them to do this }\end{array}$} \\
\hline $\begin{array}{l}\text { The Stalled: Subtype } \\
\text { - Pressures of Life }\end{array}$ & $\begin{array}{l}\text { Those Stalled by Pressures of Life may be interested in } \\
\text { the benefits of EWI, but have little or no capacity at } \\
\text { present to undertake a renovation project, even if it } \\
\text { is at no cost. Essential repairs only will be made }\end{array}$ & \\
\hline
\end{tabular}

decision-maker whose preferences take priority. Attempts to develop mass customization approaches to domestic retrofit have been explored, e.g. by E.ON (Madlener, 2013) where they identified the importance of the householder as the decision-maker, by presenting them with a range of retrofit packages to suit their individual behaviour and house, which enables the customer to participate in the design of the retrofit package, ensuring it meets their needs.

\section{Conclusions}

The personas presented in this paper have been created from detailed qualitative data from a small sample of people who live in owner-occupied, solid-wall dwellings in the UK. They provide an insight into the different types of householders in relation to home improvements. This enables the creation of a more targeted and tangible representation of end users when considering energy efficient interventions. The personas can be used by policy-makers to consider how future policies might be taken up by different sectors of the population, especially important when energy saving is not a priority for home owners. Supported by quantitative market segmentation data, this could provide clear insight into the penetration of future policies. Energy providers can use the personas to develop business models that relate to specific parts of the market, testing their potential by considering the core customer groups. Similarly, designers and technology developers can use the personas in the early stages of development, to ensure they have a target user in mind. This will prevent energy technologies from being developed blindly, with no mind to the likely users; rather, as one of the respondents in the evaluation said: 'to focus engineers on people'. They provide an insight into the range of different types of people, so that they are not treated as a homogeneous group, and so solutions to aid domestic energy renovation are better targeted to owner-occupiers and more likely to be successfully adopted.

\section{Acknowledgements}

Thanks are extended to the participants, without whom this study would not have been possible, and to Dr Becky Mallaband, who collected a substantial portion of the interview data. The authors are also grateful to the reviewers who provided detailed feedback on the draft paper.

\section{Funding}

This work formed part of the CALEBRE Project funded by the Research Councils UK Energy Programme and E.ON, to whom the authors express their gratitude. It formed part of project CALEBRE (Consumer-Appealing Low Energy Technologies for Building Retrofitting) [grant number EP/G000387/1] funded by RCUK and E.ON. The full set of personas is available on request from the authors. Access to the underlying research data is restricted as participants may be identifiable.

\section{References}

Adlin, T., \& Pruitt, J. (2010). The essential persona lifecycle: Your guide to building and using personas. San Francisco, CA: Morgan Kaufmann Publishers. 
Baum, S., \& Hassan, R. (1999). Home owners, home renovation and residential mobility. Journal of Sociology, 35(1), 23-41. doi:10.1177/144078339903500102

Brechin, E. (2008). Reconciling market segments and personas. Cooper Journal. Retrieved from http://urli.st/\#wJuPersonas/7kf-Reconciling-market-segments-and-personasCooper-Journal

Cooper, A. (1999). The inmates are running the asylum. Indianapolis: Macmillan Computer Publishing.

Cooper, A., \& Reimann, R. M. (2003). About Face 2.0: The essentials of interaction design. Indianapolis, IN: Wiley.

Department for Environment, Food and Rural Affairs (DEFRA). (2008a). Energy Analysis Focus Report. A study of Hard to Treat Homes using the English House Condition Survey. Part 1: Dwelling and Household Characteristics of Hard to Treat Homes. London: Author. Retrieved from http:// randd.defra.gov.uk/Document.aspx?Document $=$ GA0218 7164_FRP.pdf

Department for Environment, Food and Rural Affairs (DEFRA). (2008b). A framework for pro-environmental behaviours. London: Author.

Department of Energy and Climate Change (DECC). (2012). Digest of United Kingdom energy statistics 2012: Long-term trends. London, UK: Author. Retrieved from https://www.gov.uk/government/uploads/system/uploads/ attachment_data/file/84178/5958-dukes-2012-long-termtrends.pdf

Department of Energy and Climate Change (DECC). (2013). English Housing Survey 2011 to 2012: Headline Report. London, UK: Author. Retrieved from: https:/www.gov.uk/ government/uploads/system/uploads/attachment_data/file/ 88370/EHS_Headline_Report_2011-2012.pdf

De Voil, N. (2010). Personas considered harmful. Retrieved from: http://www.devoil.com/papers/ PersonasConsideredHarmful.pdf

Dorst, K., \& Cross, N. (2001). Creativity in the design process: Co-evolution of problem-solution. Design Studies, 22(5), 425-437.

Earl, P. E., \& Peng, T. (2011). Home improvements. In S Cameron (Ed.), Handbook on the economics of leisure. (pp. 197-220). Cheltenham: Edward Elgar Publishing Limited.

Energy Saving Trust. (2011). Trigger points: A convenient truth. Retrieved from http://www.energysavingtrust.org.uk/ Publications2/Corporate/Research-and-insights/TriggerPoints-a-convenient-truth

Fawcett, T. (2013). Exploring the time dimension of low carbon retrofit: Owner-occupied housing. Building Research \& Information. Advance online publication. doi:10.1080/ 09613218.2013.804769

Fawcett, T., \& Mayne, R. (2012). Exploring an 'over time' model of eco-renovation. Retrofit 2012. Salford, Manchester, 24-26 January 2012.

Firth, S. K., Lomas, K. J., \& Wright, A. J. (2010). Targeting household energy-efficiency measures using sensitivity analysis. Building Research \& Information, 38(1), 25-41. doi:10. 1080/09613210903236706

Goodwin, K. (2010). Designing for the digital age: How to create human-centred products and services. Indianapolis, IN Wiley Publishing.

Gould, J. D., \& Lewis, C. (1985). Designing for usability: Key principles and what designers think. Communications of the ACM, 28(3), 300-311. doi:10.1145/3166.3170

Gram-Hanssen, K. (2014). Existing buildings - Users, renovations and energy policy. Renewable Energy, 61, 136-140. doi.org/10.1016/j.renene.2013.05.004

Hackos, J. T., \& Redish, J. C. (1998). User and task analysis for interface design. New York: Wiley.

Haines, V. J. A., Mitchell, V. A., \& Mallaband, R. A. L. (2012) Merging a practice-orientated approach with an engineering- driven product development: A case study on home improvement. Journal of Design Research. Special issue on Design, Sustainability and Behaviour, 10(1/2), 28-49. doi:10.1504/ JDR.2012.046138

Halifax. (2010). The British home owner: Shelling out $£ 1000$ more than last year on DIY [press release]. London: Lloyd Banking Group. Retrieved from: http://www. lloydsbankinggroup.com/media/pdfs/halifax/2010/5010 pressrelease.pdf

Hewitt, N. J. (2012). Retrofit of existing buildings - A major technical, economic and social challenge. International Journal of Ambient Energy, 33(1), 1-1. doi:10.1080/ 01430750.2012 .666893

Hills, S., \& Worthing, D. (2006). Private home, public cultural asset: The maintenance behaviour of listed building owneroccupiers. Journal of Housing and the Built Environment, 21(2), 203-213. doi:10.1007/s10901-006-9043-8

Kujala, S., \& Kauppinen, M. (2004). Identifying and selecting users for user-centered design. In Proceedings of the third Nordic conference on Human-computer interaction, October 23-27, 2004, Tampere, Finland, (pp. 297-303). New York, NY: ACM. doi:10.1145/1028014.1028060

Madlener, R. (2013). Mass customization for residential energy retrofits. E.ON Energy Research Centre [online]. Retrieved from: http://www.eonerc.rwth-aachen.de/aw/cms/website/ zielgruppen/fcn/research_fcn/research_projects/ablagestruktur/ $\sim$ vty/Mass-Customization-for-Residential-Energ/?lang=en

Mallaband, B., Haines, V. \& Mitchell, V. (2013a). Exploring Past Home Improvement Experiences to Develop Future Energy Saving Technologies. Methods for Studying Technology in the Home Workshop, ACM SIGCHI Conference on Human Factors in Computing Systems (CHI), Paris, France 27th April - 2nd May 2013.

Mallaband, B., Haines, V., \& Mitchell, V. (2013b). Barriers to domestic retrofit - Learning from past home improvement experiences. In Swan, W., \& Brown, P. (Eds.), Retrofitting of the built environment (pp. 184-199). Chichester: John Wiley \& Sons.

Mallaband, R. A., Haines, V. J. A. \& Mitchell, V. A. (2012). Barriers to domestic retrofit - learning from past home improvement experiences. Retrofit 2012. University of Salford, 24-26 January 2012.

Marshall, R., Cook, S., Mitchell, V., Summerskill, S., Haines, V., Maguire, M., ... Case, K. (2013). Design and evaluation: End users, user datasets and personas. Applied Ergonomics, Advance online publication. doi:10.1016/j.apergo.2013.03. 008

Massanari, A. L. (2010). Designing for imaginary friends: Information architecture, personas and the politics of user-centered design. New Media \& Society, 12(3), 401-416.

McKay, E. (2013). UI is communication: How to design intuitive, user centered interfaces by focusing on effective communication. San Francisco, CA: Morgan Kaufmann Publishers.

Mulder, S., \& Yaar, Z. (2006). The user is always right: A practical guide to creating and using personas for the web (Voices That Matter). Berkeley, CA: New Riders.

Munro, M., \& Leather, P. (2000). Nest-building or investing in the future? Owner-occupiers' home improvement behaviour. Policy \& Politics, 28(4), 511-526.

Peng, T-C. (2012). A microstructral analysis of housing renovation decisions in Brisbane, Australia. New Zealand Economic Papers, 47(2), 158-187. doi:10.1080/00779954. 2012.704667.

Peng, T-C. (2013). An institutional economic analysis of the decision to Do-it yourself in housing renovation. Urban Studies, 50(9), 1796-1816. doi:10.1177/0042098012468343.

Phipps, A., (1983). Housing renovation by recent movers into the core neighborhoods of Saskatoon. Canadian Geographer, 27(3), 240-262. 
Pragnell, M., Spence, L., \& Moore, R. (2000). The market potential for Smart Homes (Joseph Rowntree Foundation). York: York Publishing Services Ltd.

Pruitt, J., \& Adlin, T. (2006). The persona lifecycle: Keeping people in mind throughout product design. San Francisco, CA: Morgan Kaufmann Publishers.

Rittel, H. W. J., \& Webber, M. M. (1973). Dilemmas in a general theory of planning. Policy Sciences, 4, 155-169. doi:10. 1007/BF01405730.

Robson, C. (2011). Real world research (3rd ed.). Chichester: John Wiley and Sons Ltd.

Saffer, D. (2007). Designing for interaction: Creating smart applications and clever devices. Berkeley, CA: New Riders.

Vadodaria, K., Loveday, D., Haines, V., Mitchell, V., \& Bayer, S. (2010). UK solid-wall dwellings: Thermal comfort, energy efficiency refurbishment and the user perspective - Some preliminary analysis from the CALEBRE project. Adapting to Change: New Thinking on Comfort. Cumberland Lodge, Windsor, UK, 9-11 April 2010. London: Network for Comfort and Energy Use in Buildings, 1-16.

Vadodaria, K., Loveday, D., \& Haines, V. (2014). Measured winter and spring-time indoor temperatures in UK homes over the period 1969 to 2010: A review and analysis. Energy Policy, 64, 252-262. doi.org/10.1016/j.enpol. 2013.07.062.
Watson, M., \& Shove, E. (2009). Product, competence, project and practice: DIY and the dynamics of craft consumption. Journal of Consumer Culture, 8(1), 69-89.

Wells, W. D. (1975). Psychographics: A critical review. Journal of Marketing Research, 12, 196-213.

Williams, C. C. (2008). Re-thinking the motives of do-it-yourself (DIY) consumers. The International Review of Retail, Distribution and Consumer Research, 18(3), 311-323. doi:10. 1080/09593960802113885

Wright, A. (2008). What is the relationship between built form and energy use in dwellings? Energy Policy, 36(12), 45444547. doi:10.1016/j.enpol.2008.09.014

Zhang, T., Siebers, P-O., \& Aickelin, U. (2012). A Three-dimensional model of residential energy consumer archetypes for local energy policy design in the UK. Energy Policy, 47, 102-110. doi:10.1016/j.enpol.2012.04.027

\section{Endnote}

${ }^{1}$ The Standard Assessment Procedure (SAP) is the methodology used by the UK Government to assess and compare the energy and environmental performance of dwellings. 